\title{
Control and data acquisition system for the rolling machine
}

\author{
Andrzej Sumorek ${ }^{1, *}$, and Marcin Buczaj ${ }^{2}$ \\ ${ }^{1}$ Lublin University of Technology, Department of Structural Mechanics, Nadbystrzycka 40, 20-618 Lublin, Poland \\ ${ }^{2}$ Lublin University of Technology, Inst. of Electrical Engineering and Electrotechn., Nadbystrzycka 38A, 20-618 Lublin, Poland
}

\begin{abstract}
Rolling machines are often used for forming flat elements or pipes. Problems occur when used to produce cylindrical elements other than pipes, or when experimental materials are used. It is required to introduce flexible control of the rolling process parameters in such cases. It is necessary to monitor the device operating parameters. When a rolling machine works with experimental materials, there are no typical control and acquisition data systems available. The article presents the concept and capabilities of the control and computer data acquisition system supporting the rolling process. The main task of software system is acquisition of force and kinetic parameters related to the analysed process of the compression during rolling. This system allows current recording and analysis of five physical values. The acquisition data application is developed in National Instruments LabVIEW environment. The software algorithm is based on the state machine. The article contains a detailed description of hardware and software implementation of the functions mentioned.
\end{abstract}

\section{Introduction}

The machining process is widely used in the metallurgical industry. The rolling process is characterised by low machining time, low material losses and resulting low production costs. Very often, optimum parameters of the rolling process are determined on an experimental basis and on the basis of employees' experience.

The development of a rolling model, including hot rolling, remains an unresolved problem. The first general, comprehensive studies on the rolling process appeared in the 1990s [1, 2]. Attempts to connect individual rolling parameters have been carried out selectively. The main parameters over which researchers work, are the linear velocity of the main forming cylinder and the speed of the mandrel on which the moulded element is placed [3, 4]. The relationship between the speed of the element being formed and its geometrical dimensions is sought $[5,6,7]$.

One of the research directions is an attempt to develop numerical models of the rolling process. Attempts were initiated at the end of the 20th century and are carried out to this day [8,9]. Such models are also available in commercial applications, and the accuracy of the selected model is a new problem [10].

To verify the model, it is required to have a test bench equipped with the possibility of modifying the rolling parameters (speed of tools, strength) - Fig. 1. At the same time, it is necessary to collect data on all key process parameters in a way that is convenient for the researcher. The system for controlling and acquiring data should be flexible, because after the first "blind" phase of tests, it will be adjusted in accordance with the acquired data [11].

The choice of the hardware and software platform of the data acquisition system is difficult because it depends on the financial resources and experience of the programmer creating the system. It is possible to build a simple, low-cost system based on prototype boards such as Raspberry $[12,13]$. One common approach is the use of hardware and software from a single manufacturer $[14,15,16]$. In the described case, the system is based on a single source: the budget USB-6008 measuring card programmed in the LabVIEW environment.

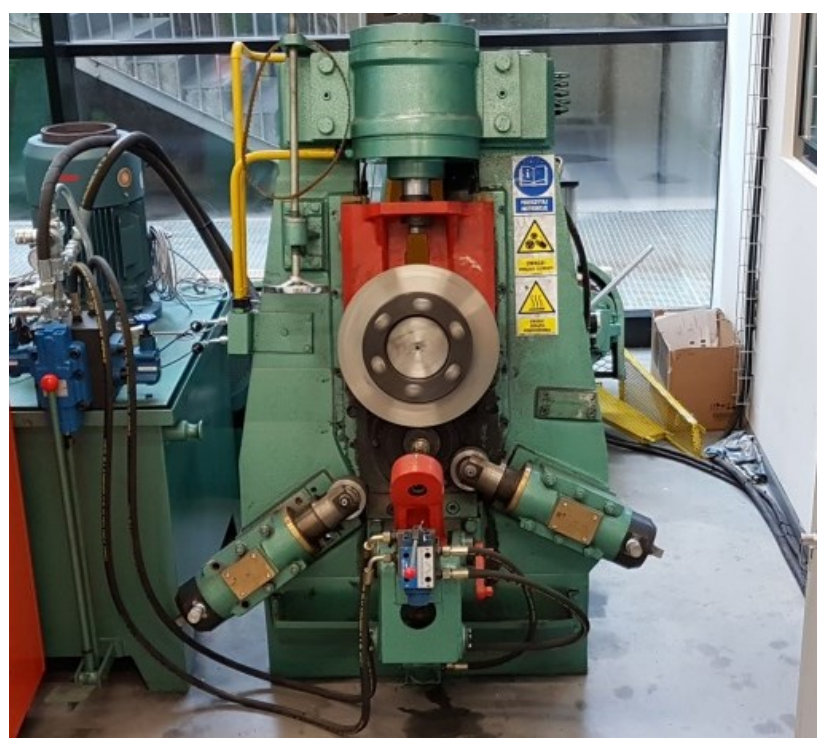

Fig. 1. General view of a ring rolling machine.

\footnotetext{
${ }^{*}$ Corresponding author: a.sumorek@pollub.pl
} 


\section{Control and data acquisition system}

As a part of the control and data acquisition system, the following modules can be distinguished: control and protection of rolling machine drive motors, a set of measuring sensors together with a measuring card, software for measuring card configuration, data acquisition and presentation.

\subsection{Hardware layer}

\subsubsection{Control system}

The rolling machine control system is based on two elements (Fig. 2):

a) a switch cabinet with a circuit breaker and signalling system,

b) a LSLV-S100 inverter (here LSLV 0370 S1004CONDS version). The S-100 inverter is mounted on the side wall of the switch cabinet (Fig. 2). The switchgear is supplied from the 230/400 V low-voltage network and protected by safeguards placed in the laboratory switchboard.

Two motors are powered from the switch cabinet:

- feed system of the rolling machine: 3-phase induction motor (manufactured by NanJing KongTe Motors Co.), type YX3-200L-4, $30 \mathrm{~kW} / 400 \mathrm{~V} / 56.6 \mathrm{~A}$ $/ 1470 \mathrm{rpm}$;

- roller pressure system: 3-phase induction motor (manufactured by NanJing KongTe Motors Co.), type YX3-160M-6, $7.5 \mathrm{~kW} / 400 \mathrm{~V} / 16.4$ A /970 rpm.

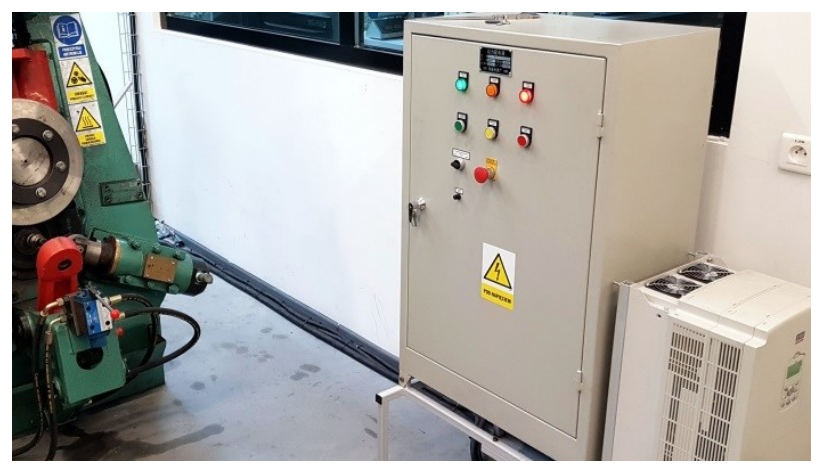

Fig. 2. The view of switch cabinet with safety control and frequency inverter.

The control process (switching on, switching off, speed control) is carried out by the rolling machine operator. The S-100 inverter allows to adjust the frequency of the supply voltage in the range of $0 \div 400$ $\mathrm{Hz}$, and thus the speed of the motor. In order to facilitate the setting of inverter settings, a frequency adjustment potentiometer is placed on the switchgear panel. The frequency adjustment range is limited by software to the range of $0 \div 60 \mathrm{~Hz}$. At the same time, motors are protected automatically against overload by means of overcurrent switches with settings equal to $1.2 \mathrm{I}_{\mathrm{n}}$ $\left(\mathrm{I}_{\mathrm{n}}\right.$ - nominal current of the motor).

\subsubsection{Data acquisition system}

The data acquisition system ensures registration of five physical values. These quantities are (Fig. 3):

- linear displacement of the working head (A),
- rotational speed of the main shaft (B),

- rotational speed of the mandrel $(\mathrm{C})$,

- oil pressure in the hydraulic cylinder at the inlet (D),

- oil pressure in the hydraulic cylinder at the outlet (E).

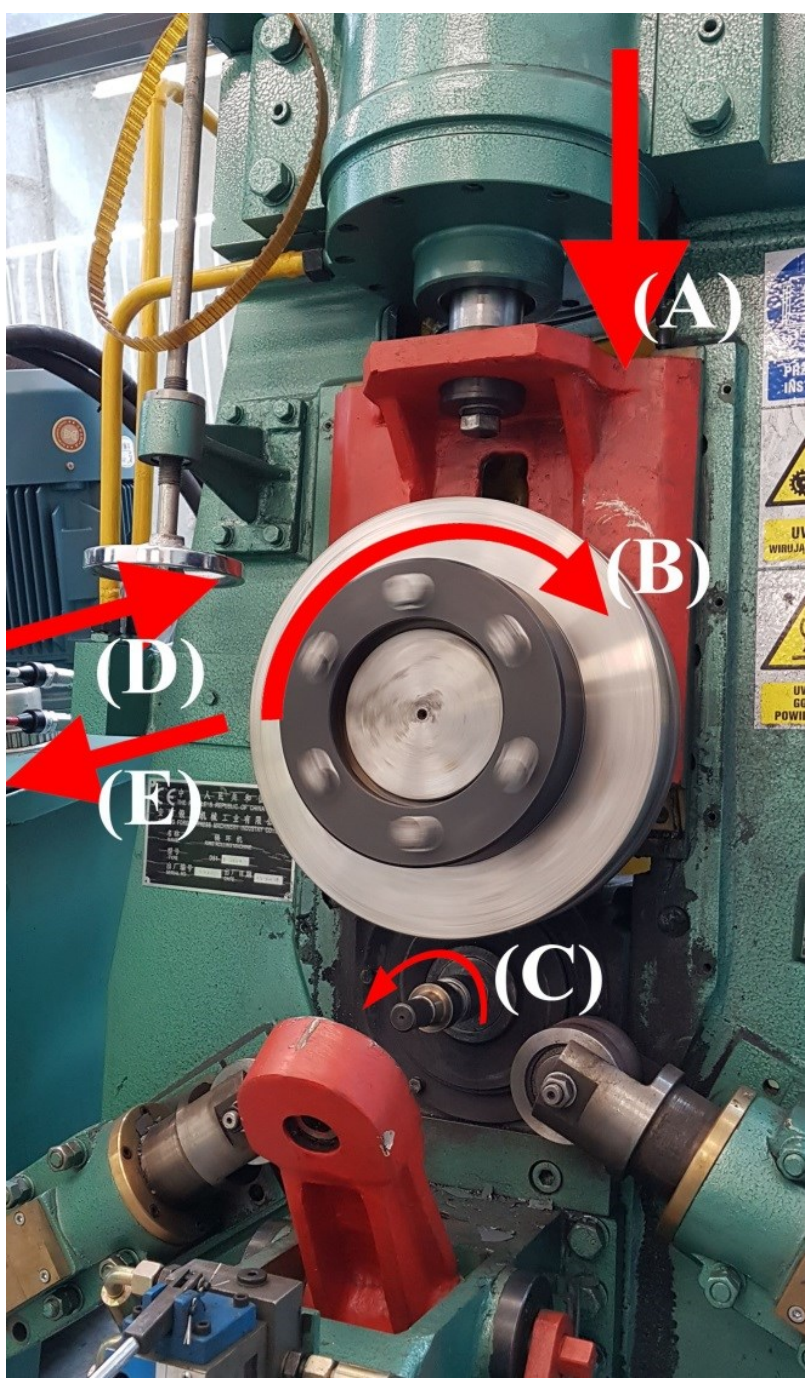

Fig. 3. Measured values: (A) - displacement - feed, (B) rotational speed of the shaft, (C) - rotational speed of the mandrel, (D) - oil pressure in the hydraulic cylinder at the inlet, (E) - outlet oil pressure.

Registration concerns the recording of 3 physical quantities (displacement, rotational speed, fluid pressure) at 5 measuring points. Mutual configuration of the elements of the control and data acquisition system is presented in Figure 4.

A displacement wire sensor WDS-300-P60-S-RU was used to record displacement of the working head (Fig. 5). Selected technical parameters of the sensor [17]: - measuring range: $300 \mathrm{~mm}$;

- linearity: $\pm 0.75 \%$ FSO;

- sensor element: hybrid-potentiometer;

- temperature range $-20 \div+80{ }^{\circ} \mathrm{C}$;

- maximal supply voltage: $32 \mathrm{~V} \mathrm{DC}$.

To register the rotational speed of the main shaft of the rolling machine and the speed of the moulded part, optoelectronic rotary-pulse MOB 1200/1026/BZ/K 
transducers were used (Fig. 6). Selected technical parameters of the sensor [18]:

- measuring range: $1200 \mathrm{imp} . /$ rotation;

- linearity: $\pm 0.75 \%$ FSO;

- maximal output frequency: $200 \mathrm{kHz}$;

- temperature range $-10 \div+70{ }^{\circ} \mathrm{C}$;

- supply voltage: $10.8 \div 26.4 \mathrm{~V} \mathrm{DC}$.

The sensor for measuring the speed of the moulded element is mounted directly on the shaft supporting the element. The sensor for measuring the rotational speed of the main shaft of the rolling machine is mounted by means of a gear reducing the rotational speed.

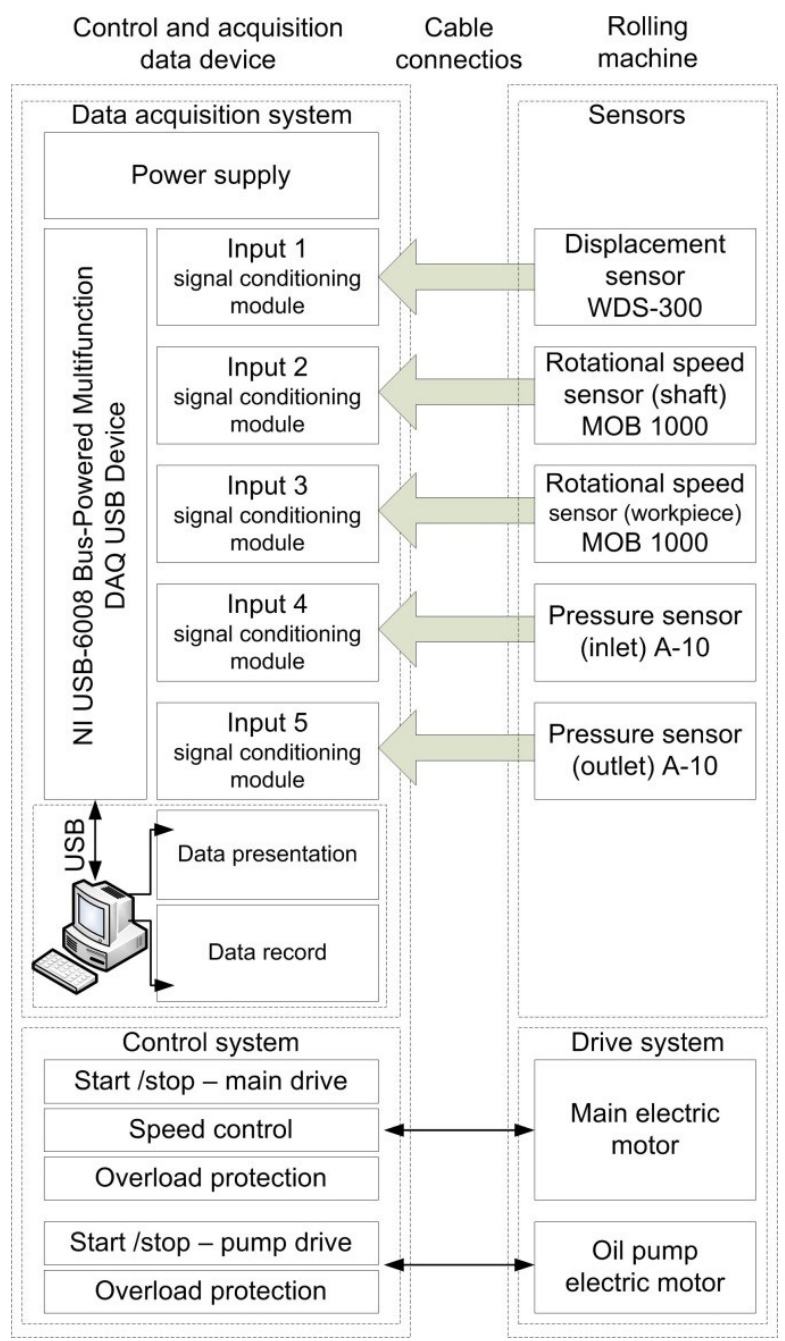

Fig. 4. A schematic diagram of the connection of the control and data acquisition system with the rolling machine.

The displacement wire sensor Wika A-10 (Fig. 7) was used to record the oil pressure at the inlet and outlet of the rolling machine head working system. Selected technical parameters of the pressure sensor [19]:

- measuring range: $0 \div 25 \mathrm{MPa}$;

- linearity: $\pm 0.50 \%$;

- output signal: $0 \div 10 \mathrm{~V} \mathrm{DC}$;

- setting time: $<4 \mathrm{~ms}$;

- temperature range $-30 \div+100{ }^{\circ} \mathrm{C}$;

- supply voltage: $14 \div 30 \mathrm{~V} \mathrm{DC}$.

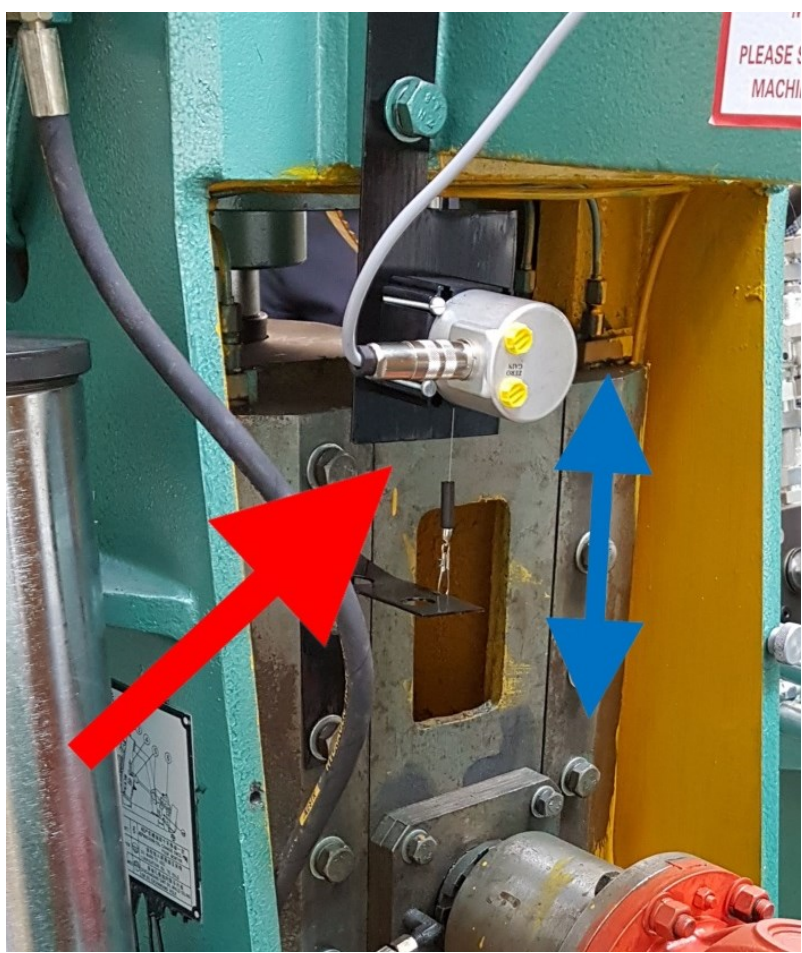

Fig. 5. Displacement sensor.

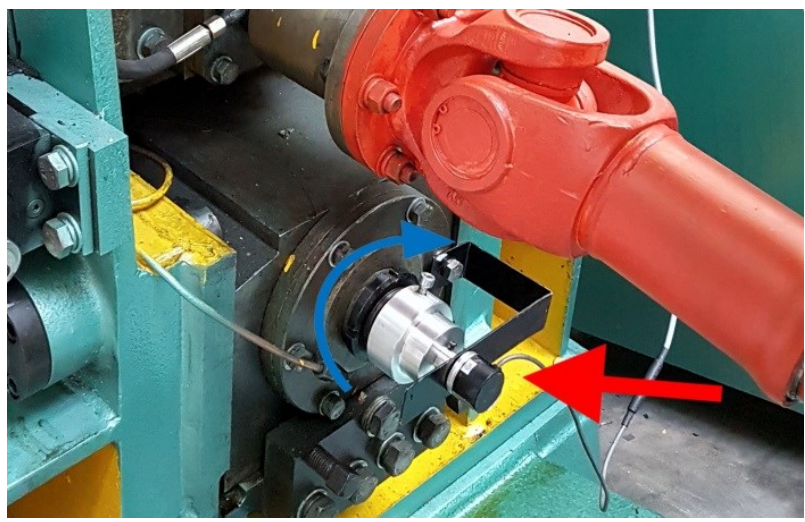

Fig. 6. Mandrel rotational speed sensor.

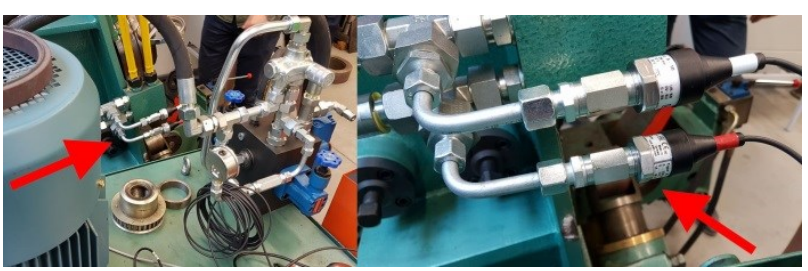

Fig. 7. Oil pressure sensors.

Data from displacement, rotational speed and oil pressure transducers are collected by a National Instruments USB-6008 measuring card (Fig. 4). The card allows the measurement and generation of both analogue and digital signals. Selected parameters of the measurement card [20]:

- single-ended analogue inputs: 8;

- differential analogue inputs: 4;

- single-ended analogue input resolution: 11 bits;

- differential analogue input resolution: 12 bits;

- single-ended input range: $\pm 10 \mathrm{~V}$; 
- maximal differential input range: $\pm 20 \mathrm{~V}$;

- maximal sampling rate: $10 \mathrm{kS} / \mathrm{s}$;

- analogue outputs: 2;

- analogue outputs resolution: 12 bits;

- absolute accuracy at full scale, single-ended: $14.7 \mathrm{mV}$;

- absolute accuracy at full scale, differential: $7.73 \mathrm{mV}$.

Input signals were connected to single-ended voltage inputs operating in the range of $\pm 10 \mathrm{~V}$. To measure the rotational speed, it would be best to use the counter type meter card inputs. The USB-6008 card has only one counter input. There is a need to operate two pulse inputs. In this case voltage inputs were also used to count pulses from the rotational speed converters. The impulses were counted based on the voltage increase of the output signals of the rotational speed converter.

\subsection{Software layer}

Data acquisition software has been implemented in a graphical development environment LabVIEW Professional Development System (2017, ver. 17.0f2, 64-bit, National Instruments). The LabVIEW development environment and the USB-6008 measurement card come from the same manufacturer. No communication problems were found between the development environment and the input device.

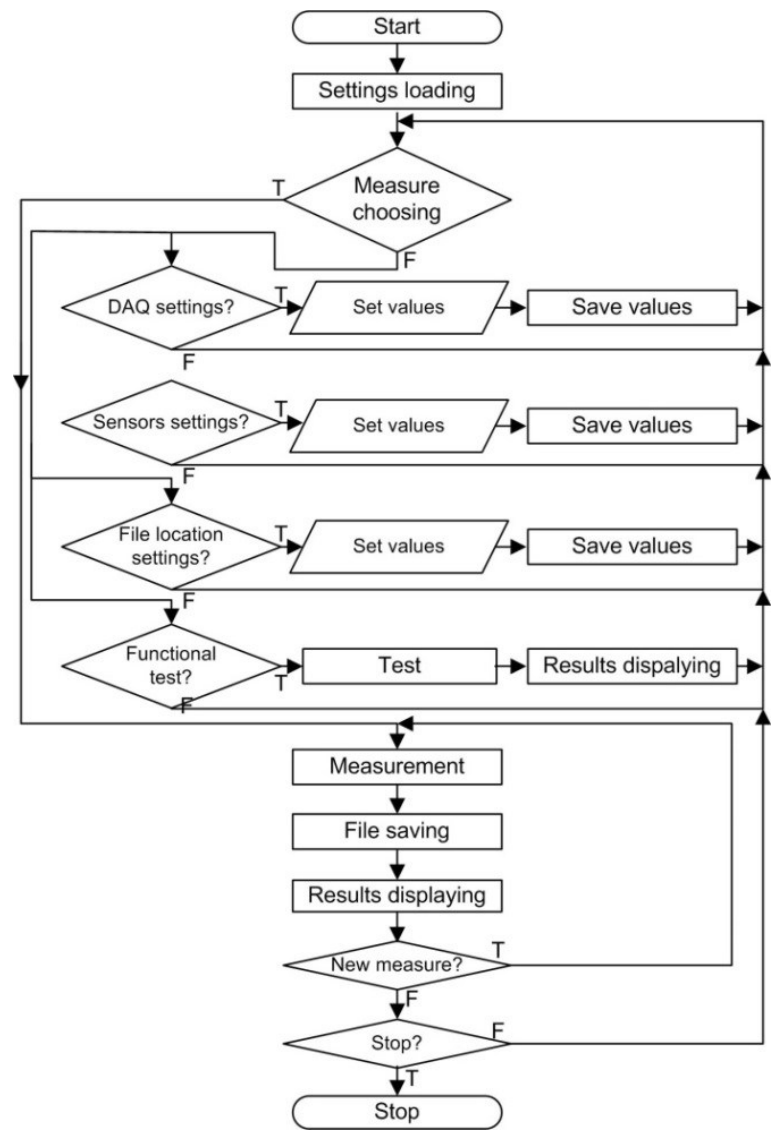

Fig. 8. Algorithm of program execution (user perspective).

The data acquisition system developed performs the following functions (Fig. 8):

- declaration of work parameters of sensors,

- declaration of the sampling rate of measurement channels,
- testing the correctness of sensor electrical connections with the measuring card,

- declaration of the place of saving the result files,

- presentation of data obtained in the measurement session,

- presentation of data stored in files,

- saving data in files in the *.tsv format (tab separated value).

The "Sensors setup" window allows to adjust the parameters of the entire sensor measurement path to personal requirements (Fig. 9). Manufacturers of the sensors used, assume a fully linear processing characteristic and the existence of a " 0 " point in the absence of a load. The window also allows to declare a rest state (zero) convenient for the researcher, and considers the loads occurring in the measurement system before starting the measurement. For example, it is possible to adjust the rotational speed of the elements depending on the diameter of the wheels used in the gears or to declare a zero position of the working head other than the zero display of the sensor.

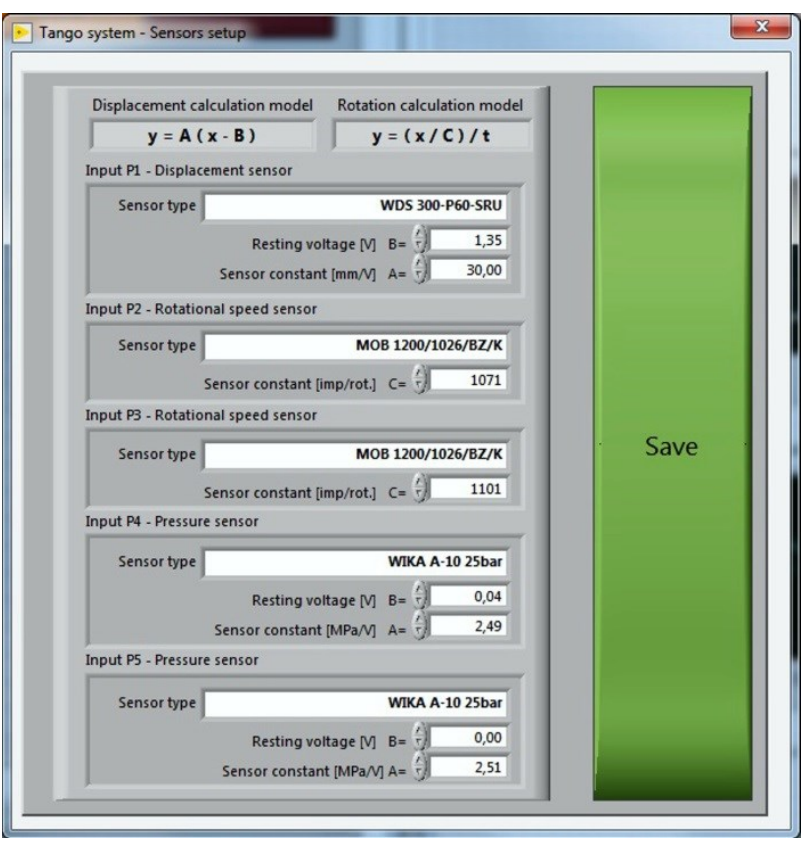

Fig. 9. Sensors setup window.

The "DAQ setup" window in the first place allows to select the measurement card installed in the system (Fig. 10). A typical operation of the entire measuring system requires its manual triggering and manual ending (using buttons on the measurement application panel). The DAQ setup window provides the setting of automatic completion of data acquisition after the working head reaches the declared position. Depending on the expected speed of the rolling process, it is possible to declare the frequency of measurements. It is possible to define the operation of all channels with a sampling frequency of 1 to 100 samples per second in all measurement channels. The maximum sampling rate of 100 samples per second was imposed by experimenters familiar with the dynamics of the rolling process. 


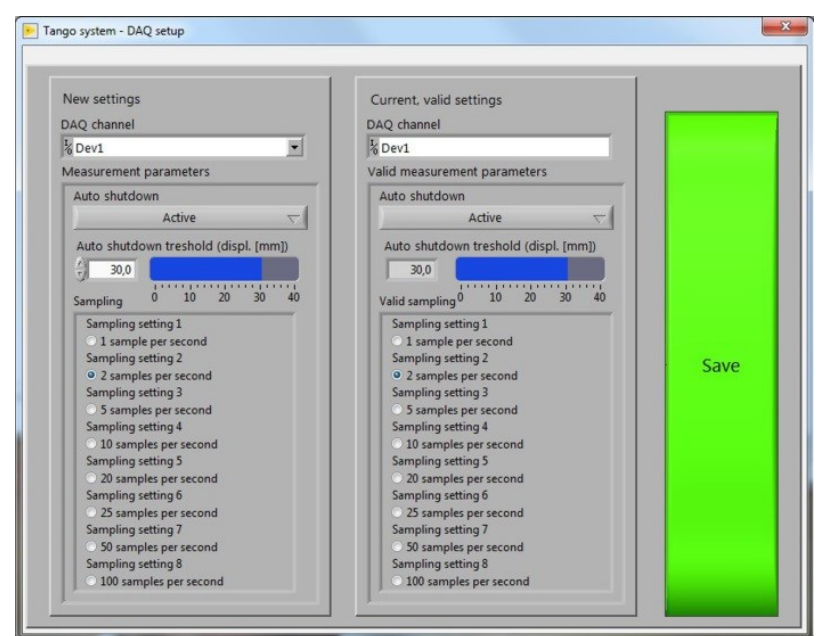

Fig. 10. DAQ setup window.

It is not possible to declare the parameters of the sensors and the measuring card in the event of damage to the electrical connections. Searching for damage is possible by calling the operation test procedure (Fig. 11, "Functional test" button). The dialogue displayed in this case presents, in a graphic form, elements with which communication has been disrupted.

Performing the correct measurement results in storing the data in the place indicated by the user. The values obtained in the current measurement process are available for viewing in graphical and text form in the main program window after selecting the "Displaying results" tab. The same card allows to view archived data after selecting the "Enter new data" button. Due to the large variety of recorded values, the range of measurement values and the amount of data, it is more convenient to view the results in software dedicated to data processing and analysis. The described system of data acquisition automatically saves data in files in the *.tsv format (tab separated value, which is transparent and supported by virtually any data processing environment).

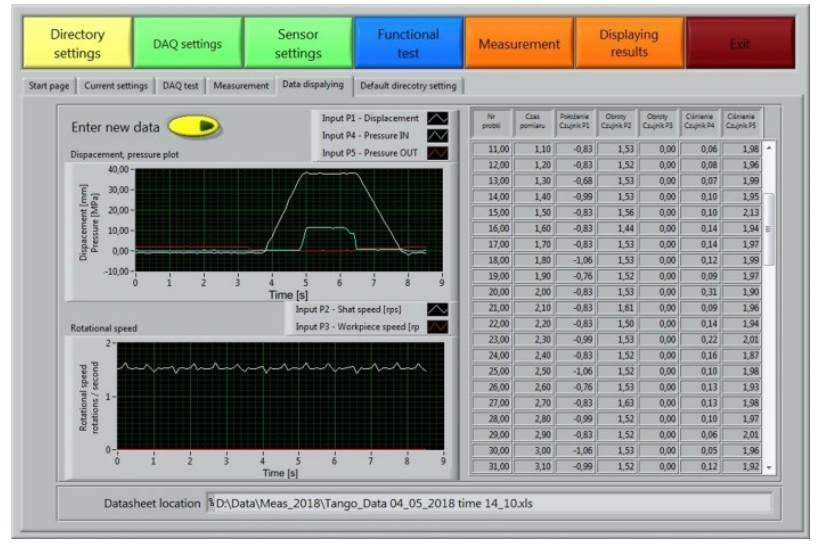

Fig. 11. Data presentation window.

\section{Practical test results}

As mentioned in the Introduction, ring rolling technology is widely used. There are no precise mathematical models that allow for forecasting the process. The developed control and data acquisition system allowed for a series of rolling trials with such materials as steel $\left(\sim 1100{ }^{\circ} \mathrm{C}\right)$, magnesium $\left(\sim 500{ }^{\circ} \mathrm{C}\right)$ or titanium $\left(\sim 900^{\circ} \mathrm{C}\right)$ (Fig. 12).

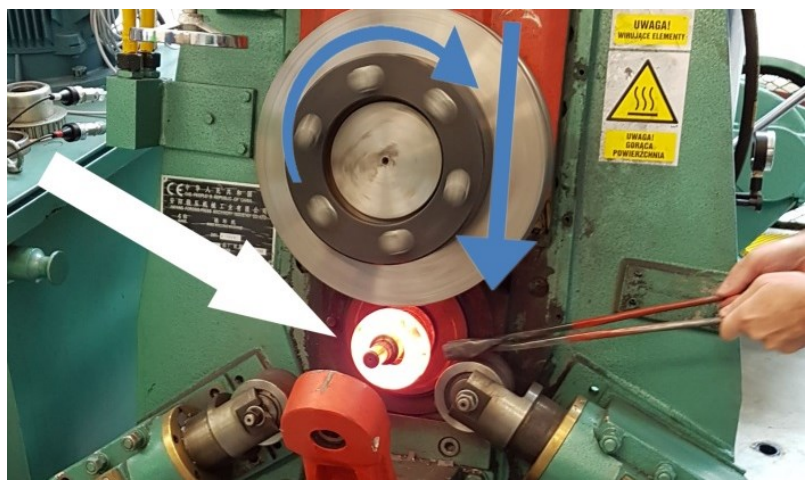

Fig. 12. A hot element during processing.

Figure 13 shows a ring element formed in the expected manner. Figure 14 contains data collected during "correct" rolling.

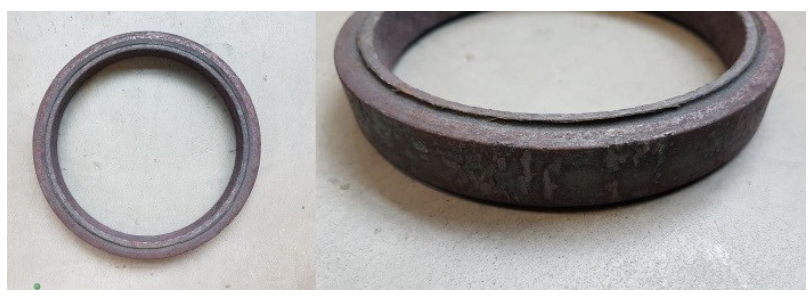

Fig. 13. A correctly formed element.

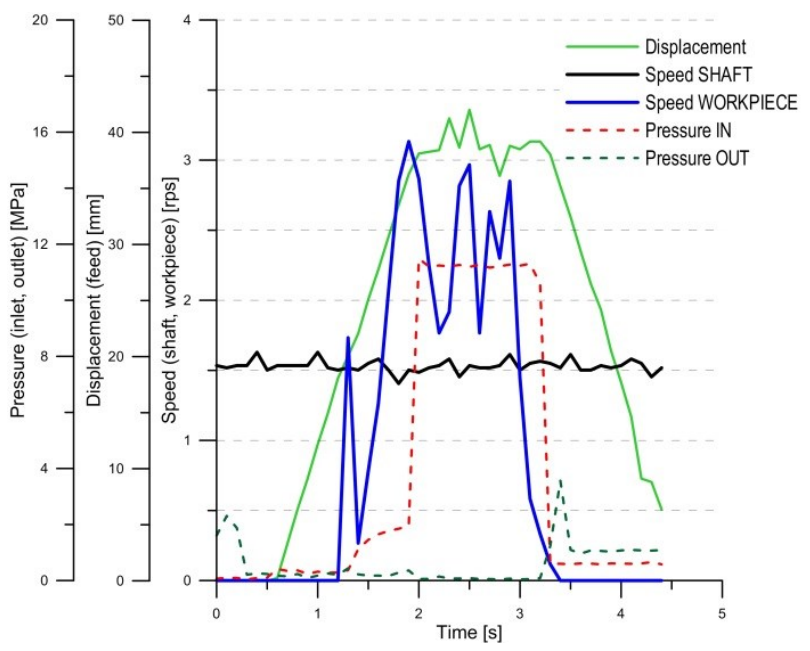

Fig. 14. The course of process parameters as a function of time for a correctly formed element.

Figure 15 shows the view of an item that was destroyed during machining. Figure 16 contains data relating to unsuccessful rolling. Although the forces applied during both processes were similar (input pressure of the working head about $11.5 \mathrm{MPa}$ ), and a similar displacement of the working head occurred (about $37 \mathrm{~mm}$ ), yet in the second case the element was damaged. The developed data acquisition system allows to indicate the differences in rotational speed of the main 
machine shaft with the working tool, i.e. about $1.55 \mathrm{rps}$ for the correct process and $1.30 \mathrm{rps}$ for the damage.

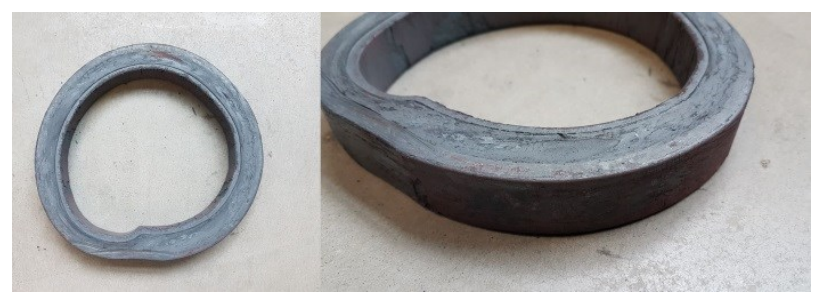

Fig. 15. A deformed element.

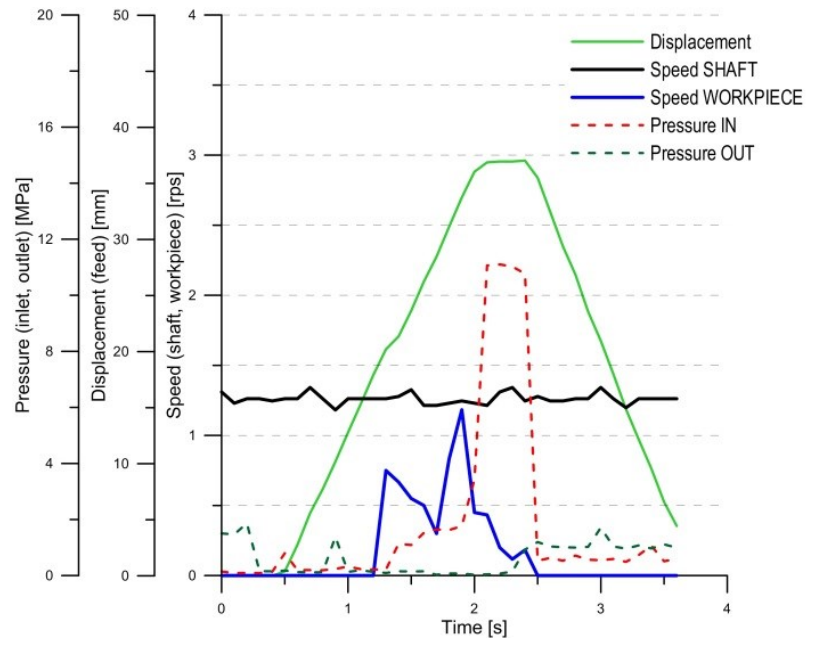

Fig. 16. The course of process parameters as a function of time for an incorrectly formed element.

\section{Conclusions}

Based on the tests of a practically implemented control system and data acquisition of a rolling machine, it was found that:

- construction of an efficient, low-cost data acquisition system (low-cost measurement card) for an industrial device working with experimental parameters is possible;

- data obtained during the tests allow the researchers to determine the parameters of the rolling machine model of work, leading to maximisation of efficiency while minimising damage to the workpieces;

- application of the LabVIEW development environment allows minimising the application development time, as it also provides the possibility of communication with measuring equipment, data processing and presentation;

- it is planned to extend the control and data acquisition system of the rolling machine with: feedback elements allowing for controlling the frequency converter, automatic shutting down of the drive system, automatic initiation of the data logging system triggered on the basis of the detection of the moment of contact of the tool with the rolled detail.

\section{References}

1. E. Erden, R. Shivpuri, Int. J. of Machine Tools and Manufacture 32, 379-398 (1992)

2. E. Erden, R. Shivpuri, Int. J. of Machine Tools and Manufacture 32, 399-413 (1992)

3. H. Lin, Z. Z. Zhi., J. of Materials Processing Technology 69, 273-276 (1997)

4. L. Xiaodong, L. Li, W. Xu, Y. Zhu, J. of Magnesium and Alloys 2, 154-158 (2014)

5. G. Lianggang, H. Yang, Int. J. of Mechanical Sciences 53, 286-299 (2011)

6. Q. Luca, G. A. Berti, Int. J. of Mechanical Sciences 115-116, 746-759 (2016)

7. P. Surdacki, A. Gontarz, The Metallurgist - Metallurgical news (in Polish) 9, 420-424 (2017)

8. K. Naksoo, M. Susumu, K. Shiro, Int. J. of Machine Tools and Manufacture 30 (4), 569-577 (1990)

9. H. Xinghui, L. Hau, G. Zhou, B. Lu, X. Wang, J. of Materials Processing Technology 214, 1245-1258 (2014)

10. P. Surdacki, A. Gontarz, The Metallurgist - Metallurgical news (in Polish) (in Polish) 3, 75-79 (2018)

11. J.P.T. Mo, A. Sinha, Engineering Systems Acquisition and Support, Woodhead Publishing, 3749 (2014)

12. J. Fletcher, W. Malalasekera, Energy 111, 32-46 (2016)

13. A.J. Lewis, M. Campbell, P. Stavroulakis, Measurement 87, 228-235 (2016)

14. F.J. Ferrero Martín, M. Valledor Llopis, J.C. Campo Rodríguez, J.R. Blanco González, J. Menéndez Blanco, Measurement 55, 265-271 (2014)

15. H.Q. Liao, Z.R. Qiu, G.H. Feng, Procedia Environmental Sciences 10 part B, 1188-1192 (2011)

16. M. Buczaj, A. Sumorek, ITM Web of Conferences 15, 1-8 (2017)

17. Micro-Epsilon, Wire sensor. Draw-wire displacement sensors, https://appmeas.co.uk/pdf/ drawwire-position-sensors/P96.pdf (rtrv 10.05.2018)

18. Megatron Elektronik $\mathrm{GmbH} \&$ Co. KG, Winkel Sensoren. Serie MOB, https://www.megatron.de/ en/products/more-products-angle-sensors/ optoelectronic-incremental-encoder-series-mob/ download/401.html (rtrv 11.02.2012)

19. WIKA Alexander Wiegand SE \& Co., KGWIKA data sheet PE 81.60 (2017)

20. National Instruments, Low-Cost, Bus-Powered Multifunction DAQ for USB, http://www.ni.com/ datasheet/pdf/en/ds-218\#detailedspecs-section (2014) 